\title{
Politics and the Twitter Revolution: A Brief Literature Review and Implications for Future Research
}

\author{
James Nguyen \\ Hanoi University, Hanoi, Vietnam \\ Email: jnguyen_hanu@hanu.vn
}

How to cite this paper: Nguyen, J. (2018) Politics and the Twitter Revolution: A Brief Literature Review and Implications for Future Research. Social Networking, 7, 243-251. https://doi.org/10.4236/sn.2018.74018

Received: October 2, 2018

Accepted: October 26, 2018

Published: October 29, 2018

Copyright $\odot 2018$ by author and Scientific Research Publishing Inc. This work is licensed under the Creative Commons Attribution International License (CC BY 4.0).

http://creativecommons.org/licenses/by/4.0/ (c) (i) Open Access

\begin{abstract}
This study conducted a review of the literature on Twitter and politics. The review is summarized under three inter-related themes: 1) does social media help politicians to be elected? 2) who benefits from social media? and 3) political polarization on Twitter. Regarding the first theme, some studies find a strong support for the argument that politicians may create electoral benefits from adopting this new technology, while others fail to find such evidence. Evidence regarding the second query is also mixed. Many have believed that underdogs may benefit the most from social media uses, but several studies challenge this claim by showing that the already established and popular politicians may be those who gain most from their Twitter uses. Taken altogether, previous evidence regarding the first and second queries is mixed. However, previous studies still find strong evidence of increasingly polarizing public opinions on Twitter and of social media's contribution to this trend.
\end{abstract}

\section{Keywords}

Twitter, Social Media, Politics

\section{Introduction}

The use of Twitter and other online platforms has been on the rise in the past years' elections [1] [2] [3] [4]. Politicians are using Twitter to engage with their supporters by sharing ideas and receiving feedback on different issues. They are now more accessible to their voters since the later can directly and instantly contact them and expect feedback in real time. Information on political issues is being shared by the public through tweets and re-tweets, and the public is able to air their grievances, ideas, and support for their preferred political candidates. 
The use of Twitter in campaigns has given all political parties an avenue where they can reach masses without incurring huge mass media costs [5].

In this study, I aim to demonstrate the effectiveness of Twitter in winning elections, the beneficiaries of Twitter and political polarization on Twitter, based on a thorough review of past literature on politics and Twitter. Specifically, I organized the literature review into following several inter-related research themes: 1) does social media help politicians to be elected? 2) who benefits from social media? and 3) political polarization on Twitter.

\section{Literature Review on Twitter and Politics}

\subsection{Does Social Media Help Politicians to Be Elected?}

A recent study [6] explores the use of Twitter in election forecasts by analyzing over 100,000 Twitter messages (or tweets) in which a political candidate or a party was mentioned before the 2009 German elections. In order to assess the emotions portrayed in those tweets, the study used text analysis software since it was important to capture the degree of emotions present in those sentiments to determine voters' preferences in politicians and parties. It was revealed that the more times a party or a politician is mentioned, the higher the chances of being elected are since these mentions were a true reflection of the election results (but see [2] [3]). Moreover, the findings of the study indicated that Twitter is a political platform which enables sharing of ideas. The high number of re-tweets recorded in the study indicated that people are intent on sharing political information and politicians can use this to increase their voters [6].

Certainly, the social media tool, Twitter, presents politicians with a strategic tool that can be used during campaigns. As noted by [7], Twitter plays a part in the re-election of a Member of Parliament (MP) in the UK. According to this study, MPs elected in 2005 were likely to use Twitter in order to get re-elected than those elected earlier, which supports the importance of social media use for electoral competition (see also [8]). Further, the study suggested that politicians who faced stiff competition from each other were likely to use Twitter to create a competitive edge. This social media tool is also used by politicians to engage the public in their achievements and to improve their image in the eyes of the electorate.

Research investigated the content of tweets and interactivity, focusing mostly on how politicians use Twitter to communicate with the citizens [5]. The study revealed that social media campaigns are becoming increasingly popular, advanced, and important in political competition. However, the study fails to find strong evidence that the use of Twitter in campaigning will create a closer relationship between politicians and their supporters [5]. While noting that Twitter gives politicians a personalized campaign tool, the study indicated that it all depends on how the candidate uses Twitter. While investigating whether the use of Twitter is effective in increasing voters for a specific candidate, the paper established that the power of Twitter in increasing the number of voters is limited 
since it is not clear whether Twitter users are a true representation of voters. That is, this study presents some evidence challenging the notion that politicians can gain electoral benefits by using social media tools such as Twitter. Research also indicated that using Twitter does not guarantee that a politician will garner additional votes because the possibility of a voter to switch from one party to another is not likely [5]. This evidence is consistent with previous findings that politicians' use of Twitter was not strongly associated with a subsequent improvement in opinion polls data ([2] [3]; see also [9]).

Another study addressed the use of Twitter during campaigns and their effect on election results by studying the German federal elections in 2009 [10]. Data on all tweet messages which had reference to a political party or specific politically used words in that season was collected. The study finds that the political party that had a huge number of supporters online was not the party that won the elections in the 2009 German federal elections. These results are noteworthy as they contradict some previous findings that report the strongly positive association between the number of online supporters and the electoral outcomes [6]. As such, a huge following on Twitter is not a prediction that a politician or a party will win an election. This evidence is also in line with some studies that fail to find any clear association between the number of Twitter followers and opinion poll data [1] [2].

\subsection{Who Benefits from Using Social Media?}

Regarding the question of "who benefits from Twitter?", a study examined the relationship between fundraising and the use of Twitter by US House Representatives [8]. This study collected campaign financial data from 415 politicians, with 298 of them having Twitter accounts. The information on their campaign funding was obtained from the Centre for Responsive Politics. The evidence indicated that those politicians who hold extreme political ideologies benefited most from using social media platforms (see also [11]). In addition, the study revealed that although the use of online social networks had no significant effect on donor contribution within a politician's constituency, it increased contributions from donors outside. Those politicians with large numbers of online followers received more donations than their counterparts with fewer followers. Lastly, the results of the study suggested that the use of social media in politics can increase the inequality in financial resources distribution among politicians [8]. This evidence is consistent with previous findings showing a strong inequality in online attention among online news outlets or journalists [12] [13] [14], organized interest groups [15] [16] [17] [18], and online blogs [19].

On the other hand, another study [20] also addressed the following two questions broadly related to the query of "who benefits from Twitter?" The first was on the degree to which presidential candidates adopted Twitter as a campaign strategy during the primary elections in 2012 [20]. The second was whether the various party candidates applied different styles on Twitter. The data was ob- 
tained from tweets posted to Democrats, Republicans, Americans Elect, and Libertarian presidential candidates in the primaries. The results indicated that the relationship between the number of posts published by a candidate on Twitter and number of followers garnered was minimal. The study revealed that those candidates who were not major party nominees used Twitter more than major party nominees (see also [21] [22]). However, the study established that high frequency of tweeting did not translate to an increase in followers, which is broadly consistent with [3]. According to the study, Democrats' presidential nominee gained the largest number of followers, although the candidate came fourth in the number of tweets and re-tweets.

The use of Twitter in different fields has been eminent in the recent past as demonstrated by [23]. The study adopted purposive sampling in selecting news articles, magazines, and newspapers to find out the characterization of Twitter by the media [23]. In the study, it was revealed that politicians using Twitter as a tool of communication can benefit significantly by communicating real-time information to their supporters, especially when participating in the legislative sessions. As such, their supporters will be involved in the process too and this builds confidence. In addition, those politicians who have fully adopted the use of Twitter and other social media platforms benefit from a large online following and their supporters are able to reach them easily.

Research also investigated the Twitter use by Australian politicians [24]. A list of politicians on Twitter was obtained and was then compared to a random sample of Australian Twitter users [24]. The evidence showed that many politicians have adopted the use of Twitter to communicate to their supporters and the public in general, although the level of success varies from one politician to another. Politicians who use Twitter more frequently had a political advantage than those who did not, as revealed by the study. However, the study did not systematically indicate why and how politicians may benefit from their political use of Twitter [24].

Online platforms provide citizens with avenues to participate and analyze election candidates during campaigns. A study examined the influence that social media had on the 2012 presidential elections in the US Data were sourced from the Twitter accounts of seven politicians running for the presidential elections [3]. The evidence from the study suggested that a relationship exists between the Twitter activities of a politician and the number of times the same politician is mentioned in a tweet. According to the study, politicians' prominence on Twitter depends on factors such as popularity and the time trend, rather than their activities on Twitter. However, the study revealed that the impact of the number of mentions in a tweet is not enough to make a statistical inference, neither is the impact on the politician's network size [3]. As ([3]; 455) puts it, "While social media does substantially expand the possible modes and methods of election campaigning, high levels of social media activity on the part of presidential candidates have, as of yet, resulted in minimal effects on the 
amount of public attention they receive online".

Another study examined the drivers of adoption of Twitter in US Congress, and suggests that politicians can reap significant benefits from their use of Twitter [25]. The study revealed that representatives who have adopted Twitter fully are able to establish networks with their peers. In addition, the study suggested that politicians who have strong support from their constituents derive transparency benefits from Twitter because they are able to share information on their day to day activities with their constituents. Finally, the study revealed that politicians who are pushing for the passing of a bill(s) will benefit from using Twitter as they will be able to reach the public and avail them with necessary information and in the process, acquire their support [25].

\subsection{Political Polarization on Twitter}

A research article by [26] analyzed political polarization on Twitter in Canada. Data were obtained from a sample of 5918 tweets that had been posted during the Canadian Federal Election in 2011 by 1492 Twitter users [26]. The results of the research concluded that there is a high political polarization on Twitter, based on the high number of political views shared by supporters of the same party. In addition, the findings indicated that supporters of a given party are unlikely to shift their loyalty to another party as a result of Twitter association and thus further reinforcing political polarization. These findings are in line with those evidenced by [5] and [11] in the study on Twitter and Campaigning.

Another study by [27] investigated political orientation and homophily in Twitter. The study used content shared on Twitter to classify Twitter users as either Republicans or Democrats [27]. According to the study, Democrats are more likely to share their ideas and political views on Twitter than Republicans. As such, Democrats possess high levels of homophily than Republicans. The study revealed that political homophily facilitates sharing of political attitudes which contribute to political polarization. However, the study indicated that the level of political polarization is higher among political activists than among the rest of the citizens.

The use of Twitter in politics knows no boundaries. A study conducted by [28] investigated political influence and communication through microblogging by analyzing tweets and re-tweets in Germany. Data for the study was obtained from the public message board of Twitter in the period leading to the two 2011 state parliament elections in Germany. Tweets that mentioned the name of politicians or their affiliated parties were collected for the purpose of the study. The study indicated that the use of Twitter in communication has contributed to political polarization. Further, it was revealed in the study that Twitter messages sentiments on political parties and issues have an effect on the process of opinion formation among Twitter users. In addition, the study established that those users with left-wing political views were more involved in discussions and thus registered more re-tweets. 
In a research paper by [29], the political alignment of Twitter Users was predicted using the content of their tweets on political issues in the period leading to the 2010 midterm elections in the US. The study used a support vector machine to predict the political affiliation of Twitter users and also analyzed political communication networks statistically to provide accurate results. The results of the study indicated that using a community structure of all the re-tweets on political issues can provide a 95 percent prediction of the political alignment of users on both extremities. To test this concept, the study used the same method to identify which websites are mostly tweeted by users who have right-leaning and left-leaning alignment, politically [29].

More recently, a study examined two views on the role played by social media platforms, with a specific focus on Twitter, in political polarization [11]. The first view addressed the personalized and customized nature of social media which increases the polarization of public opinions [11]. The second view addressed the open and easy access nature of social media which enables the public to give their opinions at any time. A sample of all the 111th US House of Representatives was selected for the study. The political ideologies of these politicians were estimated using their political preferences as evidenced in their voting documentations. The study revealed that politicians who have extreme political ideologies had a large number of online followers on Twitter and other platforms, indicating that a strong political polarization on Twitter is experienced, thereby supporting the first view ([11]; see also [8] [30] [31] [32]).

\section{Conclusions}

This study has explored the political implications of the new information technology, social media tool Twitter, by conducting a review of past literature on Twitter and politics. To do so, I organized the literature review into three inter-related research themes: 1) does social media help politicians be elected? 2) who benefits from social media? and 3) political polarization on Twitter. The first group of research has produced somewhat mixed evidence; some studies find a strong support for the argument that politicians can create significant electoral benefits from adopting this new technology [6], whereas others fail to find such strong evidence [3]. The second question of "who benefits from using social media?" is also mixed at best. Many scholars and commentators have believed that underdogs may utilize this new information technology to compete against the mainstream politicians. However, several studies challenge this claim by showing that the already established and popular politicians are those who gain most from their Twitter use (e.g., [8]; see also [16]). Taken altogether, this study concludes that previous evidence regarding the first and second queries is mixed at best and calls for additional empirical investigations on these topics.

Regarding the third topic, however, previous studies tend to find a strong support. That is, studies tend to find evidence of increasingly polarizing opinions on social media tools such as Twitter. Such polarization on Twitter may be 
the outcome of "echo chambers" phenomenon, as argued by previous studies [11] [33] [34]. For instance, ([11]; 777) argues that "the highly fragmented, customized, and niche-oriented aspects of social media and suggests these venues foster greater political polarization of public opinion". Future studies may build on these existing works to identify how one may reduce such polarization increasingly observed on these new online platforms and protect democracy.

\section{Conflicts of Interest}

The author declares no conflicts of interest regarding the publication of this paper.

\section{References}

[1] Garrett, S. (2016) The Digital Battleground: The Political Pulpit to Political Profile. Celebration of Learning.

[2] Hong, S. and Nadler, D. (2011) Does the Early Bird Move the Polls? The Use of the Social Media Tool 'Twitter' by US Politicians and Its Impact on Public Opinion. Proceedings of the 12 th Annual International Digital Government Research Conference: Digital Government Innovation in Challenging Times, College Park, 12-15 June 2011, 182-186. https://doi.org/10.1145/2037556.2037583

[3] Hong, S. and Nadler, D. (2012) Which Candidates Do the Public Discuss Online in an Election Campaign? The Use of Social Media by 2012 Presidential Candidates and Its Impact on Candidate Salience. Government Information Quarterly, 29, 455-461. https://doi.org/10.1016/j.giq.2012.06.004

[4] Omri, M. (2016) Every Tweet Counts: Examining Spatial Variability of Twitter Data Representativeness. Master Thesis, Graduate School of the University of Oregon, Eugene.

[5] Vergeer, M. (2015) Twitter and Political Campaigning. Sociology Compass, 9, 745-760. https://doi.org/10.1111/soc4.12294

[6] Tumasjan, A., Sprenger, T.O., Sandner, P.G. and Welpe, I.M. (2011) Election Forecasts with Twitter: How 140 Characters Reflect the Political Landscape. Social science Computer Review, 29, 402-418. https://doi.org/10.1177/0894439310386557

[7] Jackson, N. and Lilleker, D. (2011) Microblogging, Constituency Service and Impression Management: UK MPs and the Use of Twitter. The Journal of Legislative Studies, 17, 86-105. https://doi.org/10.1080/13572334.2011.545181

[8] Hong, S. (2013) Who Benefits from Twitter? Social Media and Political Competition in the US House of Representatives. Government Information Quarterly, 30, 464-472. https://doi.org/10.1016/j.giq.2013.05.009

[9] Smoliarova, A.S., Bodrunova, S.S. and Blekanov, I.S. (2017) Politicians Driving Online Discussions: Are Institutionalized Influencers Top Twitter Users? International Conference on Internet Science, Thessaloniki, 22-24 November 2017, 132-147. https://doi.org/10.1007/978-3-319-70284-1_11

[10] Jungherr, A., Jürgens, P. and Schoen, H. (2012) Why the Pirate Party Won the German Election of 2009 or the Trouble with Predictions: A Response to Tumasjan, a., Sprenger, to, Sander, pg, \& welpe, im "Predicting Elections with Twitter: What 140 Characters Reveal about Political Sentiment". Social Science Computer Review, 30, 229-234. https://doi.org/10.1177/0894439311404119

[11] Hong, S. and Kim, S.H. (2016) Political Polarization on Twitter: Implications for the 
Use of Social Media in Digital Governments. Government Information Quarterly, 33, 777-782. https://doi.org/10.1016/j.giq.2016.04.007

[12] Hong, S. (2012) Online News on Twitter: Newspapers' Social Media Adoption and Their Online Readership. Information Economics and Policy, 24, 69-74. https://doi.org/10.1016/j.infoecopol.2012.01.004

[13] Adcock, C. (2016) Leveraging the Social Network: How Journalists and News Organizations Connect with Readers on Twitter. https://shareok.org/handle/11244/34683

[14] Doğu, B. (2017) Turkey's News Media Landscape in Twitter: Mapping Interconnections among Diversity. Journalism. https://doi.org/10.1177/1464884917713791

[15] Hong, S. and Nadler, D. (2015) Social Media and Political Voices of Organized Interest Groups: A Descriptive Analysis. Proceedings of the 16th Annual International Conference on Digital Government Research, Phoenix, 27-30 May 2015, 210-216. https://doi.org/10.1145/2757401.2757416

[16] Hong, S. and Nadler, D. (2016) The Unheavenly Chorus: Political Voices of Organized Interests on Social Media. Policy \& Internet, 8, 91-106. https://doi.org/10.1002/poi3.110

[17] Kanol, D. and Nat, M. (2017) Interest Groups and Social Media: An Examination of Cause and Sectional Groups' Social Media Strategies in the EU. Journal of Public Affairs, 17, e1649. https://doi.org/10.1002/pa.1649

[18] Whitesell, A. (2018) Interest Groups and Social Media in the Age of the Twitter President. Politics, Groups, and Identities. https://doi.org/10.1080/21565503.2018.1518785

[19] Hindman, M. (2008) The Myth of Digital Democracy. Princeton University Press, Princeton.

[20] Conway, B.A., Kenski, K. and Wang, D. (2013) Twitter Use by Presidential Primary Candidates during the 2012 Campaign. American Behavioral Scientist, 57, 1596-1610. https://doi.org/10.1177/0002764213489014

[21] Ahmed, S. and Skoric, M. (2015) Twitter and 2013 Pakistan General Election: The Case of David 2.0 against Goliaths. In: Case Studies in e-Government 2.0, Springer, Cham, 139-161. https://doi.org/10.1007/978-3-319-08081-9_9

[22] Steinfeld, N. (2016) The F-Campaign: A Discourse Network Analysis of Party Leaders' Campaign Statements on Facebook. Israel Affairs, 22, 743-759. https://doi.org/10.1080/13537121.2016.1174385

[23] Arceneaux, N. and Schmitz Weiss, A. (2010) Seems Stupid until You Try It: Press Coverage of Twitter, 2006-9. New Media \& Society, 12, 1262-1279. https://doi.org/10.1177/1461444809360773

[24] Grant, W.J. and Moon, B. (2010) Digital Dialogue? Australian Politicians' Use of the Social Network Tool Twitter. Australian Journal of Political Science, 45, 579-604. https://doi.org/10.1080/10361146.2010.517176

[25] Chi, F. and Yang, N. (2010) Twitter in Congress: Outreach vs. Transvparency.

[26] Gruzd, A. and Roy, J. (2014) Investigating Political Polarization on Twitter: A Canadian Perspective. Policy \& Internet, 6, 28-45.

https://doi.org/10.1002/1944-2866.POI354

[27] Colleoni, E., Rozza, A. and Arvidsson, A. (2014) Echo Chamber or Public Sphere? Predicting Political Orientation and Measuring Political Homophily in Twitter Using Big Data. Journal of Communication, 64, 317-332.

https://doi.org/10.1111/jcom.12084 
[28] Stieglitz, S. and Dang-Xuan, L. (2012) Political Communication and Influence through Microblogging-An Empirical Analysis of Sentiment in Twitter Messages and Retweet Behavior. 45th Hawaii International Conference on System Science, Maui, 4-7 January 7 2012, 3500-3509. https://doi.org/10.1109/HICSS.2012.476

[29] Conover, M.D., Gonçalves, B., Ratkiewicz, J., Flammini, A. and Menczer, F. (2011) Predicting the Political Alignment of Twitter Users. IEEE 3rd International Conference on Social Computing, IEEE 3rd International Conference on Privacy, Security, Risk and Trust, Boston, 9-11 October 2011, 192-199.

https://doi.org/10.1109/PASSAT/SocialCom.2011.34

[30] Gollwitzer, A. (2018) Social Media Use Relates to Perceiving the United States as More Politically Polarized.

[31] Interian, R. and Ribeiro, C.C. (2018) An Empirical Investigation of Network Polarization. Applied Mathematics and Computation, 339, 651-662.

https://doi.org/10.1016/j.amc.2018.07.066

[32] Kim, S.H. and Hong, S. (2015) Political Ideology Matter in Online Salience? Evidence from Social Media Use by Members of the Korean National Assembly. In: Proceedings of the 16th Annual International Conference on Digital Government Research, ACM, New York, 197-203. https://doi.org/10.1145/2757401.2757415

[33] Sunstein, C.R. (2018) Republic: Divided Democracy in the Age of Social Media. Princeton University Press, Princeton.

[34] Hong, S. and Kim, N. (2018) Will the Internet Promote Democracy? Search Engines, Concentration of Online News Readership, and e-Democracy. Journal of Information Technology \& Politics. 